\title{
Transgenic model of cardiac rhabdomyosarcoma formation
}

\author{
Christiane Köbbert, PhD, ${ }^{a, b}$ Christa Möllmann, ${ }^{a, b}$ Michael Schäfers, MD, ${ }^{c}$ Sven Hermann, MD, ${ }^{c}$ Hideo A. Baba, MD, ${ }^{d}$ \\ Andreas Hoffmeier, MD, ${ }^{e}$ Günter Breithardt, MD, ${ }^{\mathrm{a}, \mathrm{b}}$ Hans H. Scheld, MD, ${ }^{\mathrm{e}}$ Gabriele Weissen-Plenz, PhD, ${ }^{\mathrm{a}, \mathrm{b}, \mathrm{e}}$ and \\ Jürgen R. Sindermann, $M D^{a, b, e}$
}

From the Departments of Cardiology and Angiology, ${ }^{a}$ Nuclear Medicine, ${ }^{\mathrm{c}}$ and Thoracic and Cardiovascular Surgery, ${ }^{\mathrm{e}}$ Hospital of the University of Münster, Münster, Germany; the Leibniz Institute for Arteriosclerosis Research, ${ }^{\text {b }}$ the University of Münster, Münster, Germany; the Institute of Pathology, ${ }^{\mathrm{d}}$ Hospital of the University of DuisburgEssen, Essen, Germany.

This work has been supported in part by an "Innovative Medical Research" grant of the University of Münster.

Received for publication Dec 16, 2007; revisions received Feb 18, 2008; accepted for publication April 20, 2008.

Address for reprints: Jürgen R. Sindermann, MD, Department of Thoracic and Cardiovascular Surgery, Hospital of the University of Münster, Albert-Schweitzer-Strasse 33 48149 Münster, Germany (E-mail: sinderm@ uni-muenster.de).

J Thorac Cardiovasc Surg 2008;136:1178 86

\section{$0022-5223 / \$ 34.00$}

Copyright $\odot 2008$ by The American Association for Thoracic Surgery

doi:10.1016/j.jtcvs.2008.04.022
Objectives: Cardiac rhabdomyosarcomas are rare, and the pathogenesis of this detrimental disease is widely unknown. Most data are obtained from case reports or small series, and models for systematic pathogenetic studies are lacking. We aimed to establish a transgenic mouse model of cardiac rhabdomyosarcoma formation.

Methods: Standard techniques were used to construct a minigene comprised of the $5^{\prime}$ region of the 1.4-kb SM22 $\alpha$ gene (expressed in embryonic cardiac muscle) and the $2.7-\mathrm{kb}$ SV40 $\mathrm{T}$ antigen early region. This $\mathrm{T}$ antigen fragment includes the coding sequences for the binding sites of p53 and the proteins of the pRb family. Genotyping of transgenic mice was performed by means of polymerase chain reaction, and phenotypic expression was evaluated by means of immunohistochemistry.

Results: Transgenic mice were studied at the age of approximately 8 to 12 weeks. Cardiac tumors were found of variable size in the left or right sides of the heart and were associated with $\mathrm{T}$ antigen expression. Histologic analysis revealed a 3.1-fold enhanced cell density, enlarged cell nuclei, and a 3.4-fold enhanced DNA content. Phenotypic characterization of cardiac tumors resulted in positive staining for desmin, smooth muscle $\alpha$-actin, troponin C, and Myo D1, which met the criteria for rhabdomyosarcomas.

Conclusions: To the best of our knowledge, the present study is the first description of a mouse model of cardiac rhabdomyosarcoma formation based on genetic modulation. Our model will be a valuable tool for illuminating the pathogenesis of cardiac rhabdomyosarcomas and will allow the testing of new therapeutic approaches to fight this dreadful disease.

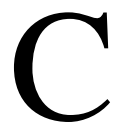
ardiac sarcomas are rare, and the pathogenesis of this disease is only incompletely understood. In the past, most data have been obtained from postmortem examination of single cases or small series. Cardiac sarcomas comprise a variety of histologic entities among which angiosarcoma, rhabdomyosarcoma, mesothelioma, and fibrosarcoma are most commonly found. Rhabdomyosarcomas make up $21 \%$ of the primary neoplasms of the heart and are the second most common in adults. ${ }^{1}$ This detrimental disease is primarily found in middle-aged patients and is characterized by a poor prognosis with a mean survival time of a few months. Pivotal understanding of the pathogenesis of sarcoma formation has been derived from studies on extracardiac sarcomas, which gave rise to specific testing of genetic translocations. ${ }^{2,3}$ However, pathologic specification of sarcoma is still a matter of histologic evaluation.

The pathogenesis of cardiac sarcoma formation is only incompletely understood. Case reports have presented cytogenetic data showing a complex caryotype of cardiac sarcoma. ${ }^{3-6}$ In some angiosarcomas mutations of $\mathrm{p} 53$ have been found, and this highlighted the pathogenetic role of this oncogene..$^{6-9}$ Furthermore, mutations of K-ras have been shown for some cardiac angiosarcomas and rhabdomyosarcomas. ${ }^{9}$ Further evidence for the causative role of the p53 pathway during cardiac sarcoma formation 


\section{Abbreviations and Acronyms \\ FDG $={ }^{18}$ F-Fluordeoxyglucose \\ PET $=$ positron emission tomography \\ $\mathrm{TAg}=$ tumor antigen}

was provided by mouse studies on exposure to 1,3-butadiene, resulting in mutations of K-ras and $\mathrm{p} 53 .{ }^{7}$ However, animal models providing insight into the pathogenesis of cardiac sarcomas, such as angiosarcomas or rhabdomyosarcomas, are lacking.

Tissue-targeted expression of the SV40 tumor antigen (TAg) in transgenic mice has been used to create specific models of proliferative disorders and malignant disease by inducing an inactivation of cell cycle-negative regulators, such as $\mathrm{p} 53^{10}$ and the proteins of the pRb family. ${ }^{11-13}$ Based on this, TAg as a viral oncoprotein has also been a focus of interest in mechanistic studies on the pathogenesis of tumors. Former studies on the cardiac expression of TAg under the control of the atrial natriuretic factor promoter brought up a model of atrial tumors featuring several cardiac-specific characteristics and an adult cardiac phenotype. ${ }^{14,15}$ Further studies were performed by expressing TAg under control of the $\alpha$ or $\beta$ myosin heavy chain promoter, resulting in hyperplasia in cardiac cells or cardiac myopathies. ${ }^{16,17}$ This suggested an approach using the targeted expression of TAg under control of the $5^{\prime}$ sequence of the SM22 $\alpha$ gene. $\mathrm{SM} 22 \alpha$ is a calponin-related, calcium-binding protein that is known for its specificity for adult smooth muscle. In addition, it is also expressed, although only transiently, in embryonic cardiac muscle. ${ }^{18,19}$ Studies on mice have shown that SM22 $\alpha$ transcripts were first expressed in vascular smooth muscle at about embryonic day 9.5 and thereafter continued to be expressed in all smooth muscle cells into adulthood. In addition, SM22 $\alpha$ was expressed transiently and very early in the heart between embryonic days 8.0 and 12.5 and in skeletal muscle in the myotomal compartment of the somites between embryonic days 9.5 and 12.5. ${ }^{18}$ Our approach of SM22 $\alpha$-targeted TAg expression gave rise to a new transgenic mouse model developing tumors featuring characteristics of cardiac rhabdomyosarcomas, thereby establishing, to the best of our knowledge, the first model of cardiac rhabdomyosarcoma formation based on genetic modulation.

\section{Materials and Methods Molecular Constructs}

Standard techniques were used to construct a minigene comprised of the 1.4-kb fragment of the SM22 $\alpha$ promoter region, as published recently, ${ }^{19}$ and the wild-type SV40 TAg early region. The TAg DNA sequence was $2.7 \mathrm{~kb}$ long (BglI/Bam HI fragment), starting at the origin of DNA replication 80 nucleotides upstream from the start codon and including the endogenous TAg splice site. The exact DNA sequence and amino acid sequence of the TAg early region have been published. ${ }^{20}$ This TAg fragment includes the coding sequences for the binding sites of p53 (residues 350-450 and 532-625) and the proteins of the pRb family (residues 105114). ${ }^{21,22}$ Orientations of fragments were confirmed by means of restriction digestion and DNA sequencing. Transcripts originating from the SM22 $\alpha$ promoter will thus target expression of TAg in the mice.

\section{Generation of Transgenic Mice}

Transgenic mice were generated in a FVB/N background by using standard techniques for microinjecting purified insert DNA into zygotes. The investigation conforms with the "Guide for the care and use of laboratory animals" published by the US National Institutes of Health and the German Law on the Care and Use of Laboratory Animals and was approved by the local institutional review board. Pups derived from the microinjected embryos were screened for the presence of the transgene by means of polymerase chain reaction amplification with primers located in the TAg gene. Internal control primers included in each reaction were sense and antisense to 2 regions of the murine connexin43 gene selected so as to amplify a readily distinguishable DNA fragment. Reaction products were analyzed by means of electrophoresis on a $1.5 \%$ agarose gel and detected by means of ethidium bromide staining. Transgene expression was tested in every transgenic mouse by using immunohistochemistry. For all analyses performed on transgenic mice, age-matched wild-type mice of the same genetic background were used as control animals.

\section{Histology, Immunohistochemistry, and Morphometry}

Tissues were dehydrated through various concentrations of ethanol and embedded in paraffin by using standard methods. Sections were rehydrated and visualized with Verhoeff-van Gieson stain and hematoxylin and eosin stain, respectively. For immunohistochemistry, tissues were blocked with phosphate-buffered saline containing bovine serum albumin and treated with $2 \% \mathrm{H}_{2} \mathrm{O}_{2}$ to inactivate endogenous peroxidases. Antigen retrieval was performed at $97^{\circ} \mathrm{C}$ for 40 minutes in citrate buffer (Dako, Carpinteria, Calif). Staining for TAg used a monoclonal antibody (diluted 1:200) specifically reacting with the $\mathrm{COOH}$-terminal end of TAg (Clone PAb 101; PharMingen, San Diego, Calif). $\alpha$-Smooth muscle actin was stained with a mouse monoclonal antibody diluted 1:1500 (Clone 1A4; Sigma, St Louis, Mo). Desmin monoclonal antibody (clone D33, Dako) and troponin polyclonal antibody C-19 (Santa Cruz Biotechnology, Santa Cruz, Calif) were used at dilution of 1:50 and 1:100, respectively. Myo D1 antibody (Clone 5.8 A, Dako) was used at a dilution of 1:50. Proliferative cell nuclear antigen was analyzed by using a mouse monoclonal antibody diluted 1:50 (Clone PC 10, Dako). Primary antibodies were labeled with streptavidinhorseradish peroxidase kits (Dako), and color development was performed with diaminobenzidine (Sigma). Sections were briefly counterstained with hematoxylin for the visualization of all nuclei. Negative controls were included that were treated identically but received no primary antibody to evaluate specific immunohistochemical staining.

DNA content of cells was evaluated by using Feulgen staining with standard methods, and automated DNA cytometric measurements were performed with CYDOK software (Hilgers, Königswinter, Germany). Morphometric analysis was performed by measuring 

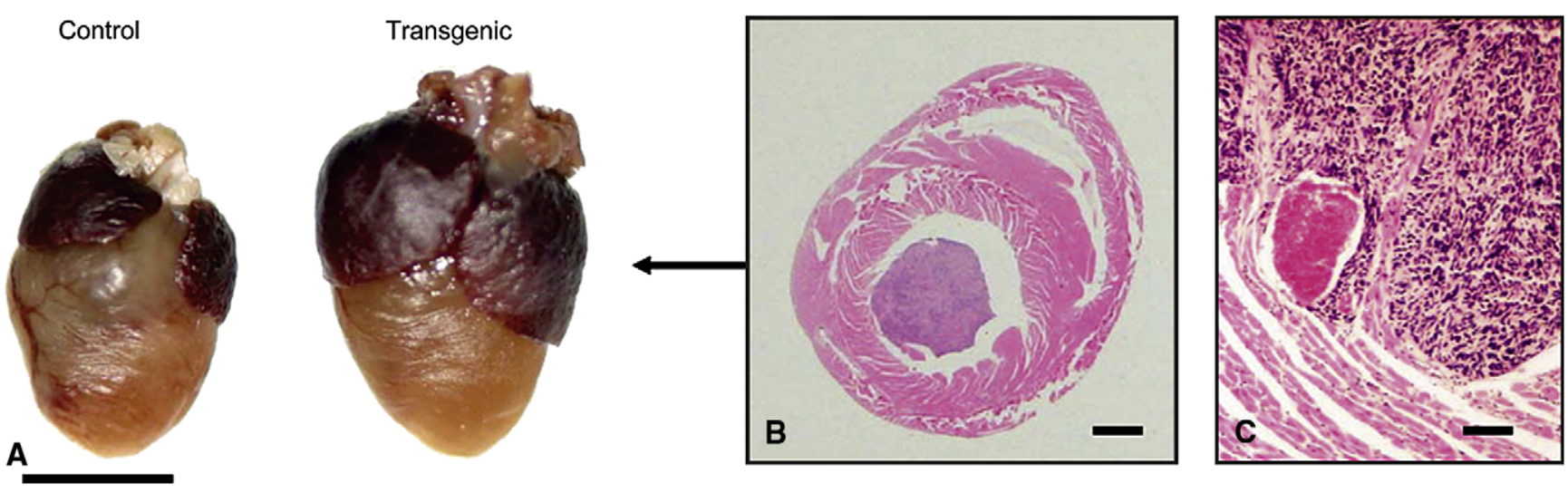

\begin{abstract}
Figure 1. Panel A shows comparative displays of the heart of an approximately 12-week-old mouse and an agematched control animal. The heart of the transgenic animal presents a giant tumor formation in the left ventricle, which is associated with an overtly enlarged right and left atrium. Panel B shows a cross-section of the same transgenic heart (arrow) stained with hematoxylin and eosin. The heart was cut at the ventricular level below the heart basis. The spherical tumor occupies about $55 \%$ of the cross-sectional luminal area of the left ventricle. Panel $\mathrm{C}$ displays tumor tissue and adjacent regular cardiac muscle of the same specimen stained with hematoxylin and eosin. A small blood-filled area is surrounded by the tumor tissue on one side and regular cardiac muscle on the other side. The tumor infiltrates between struts of regular cardiac muscle. Tissues were prepared as described in the Methods section. Bars: A, 5 mm; B, 1 mm; C, $100 \mu \mathrm{m}$.
\end{abstract}

the circumference of the external and internal elastic lamina of 3 cross-sections of the descending thoracic aorta for each animal. Areas were calculated from circumference measurements, assuming a circular structure under in vivo conditions. Age-matched mice of the same genetic background (siblings) were used as control animals. Cellular cross-sectional density was determined by counting area-defined representative microscopic fields and relating the cell number to the areas for transgenic animals and age-matched control animals.

\section{Positron Emission Tomography}

Positron emission tomography (PET) was performed by using the 32-module quadHIDAC scanner (Oxford Positron Systems, Weston-on-the-Green, United Kingdom) dedicated to small-animal imaging to evaluate the detection of cardiac tumors and its signal intensity in relation to the cardiac walls. The scanner has an effective resolution of $0.7 \mathrm{~mm}$ full width at half maximum (FWHM) in the transaxial and axial directions when using an iterative resolution recovery reconstruction algorithm. ${ }^{23}$ Animals were anesthetized with isoflurane $(1.5 \%)$ and placed on a heating pad to maintain a body temperature within the normal range. ${ }^{18}$ F-Fluordeoxyglucose (FDG; $10 \mathrm{MBq}$ ) in $100 \mu \mathrm{L}$ of $0.9 \%$ saline was injected intravenously 1 hour before each scan. PET list mode data were acquired for 15 minutes and subsequently reconstructed into a single-image volume with a voxel size of $0.4 \times 0.4 \times 0.4 \mathrm{~mm}^{3}$. From the 3 -dimensional volume data, transverse slices through the whole body and reoriented slices through the heart in the short axis, horizontal long axis, and vertical long axis were generated.

\section{Statistical Analysis}

Data are presented as means \pm standard deviation. Statistical significance was assessed by using the Student's $t$ test for independent samples.

\section{Results}

\section{General Phenotypic Characteristics of Transgenic Mice}

Microinjection of purified insert DNA into zygotes resulted in the generation of 3 independent founders (male and female). One founder lacked phenotypic transgene expression, one founder failed to generate a mouse line because of embryonic or newborn death of offspring, and one male founder gave rise to a transgenic mouse line featuring transgene expression. Offspring mice of this latter line were included in this study at the age of approximately 8 to 12 weeks. Transgene expression was found in both male and female mice and was found in smooth muscle tissue of the vessels, the gastrointestinal tract, and the genitourinary tract. Ten mice were screened for cardiac tumor formation, which was found in 8 hearts, as explained below. Age matched wild-type siblings were used as control animals. Transgenic mice were indistinguishable from control animals in terms of size and body weight.

\section{Cardiac Phenotype}

Cardiac tumors were found in 8 transgenic mice. These tumors were of variable size in the left or right side of the heart. In contrast, wild-type control siblings lacked tumor formation. Figure 1 depicts the heart of an approximately 12week-old mouse showing a large tumor in the left ventricle, which, because of hemodynamic compromise, might have caused an enlargement of both atria (Figure 1, A). Figure 1, $B$, displays a cross-section of the same heart showing the large tumor of the left ventricle (Figure 1, $C$, reveals a higher 

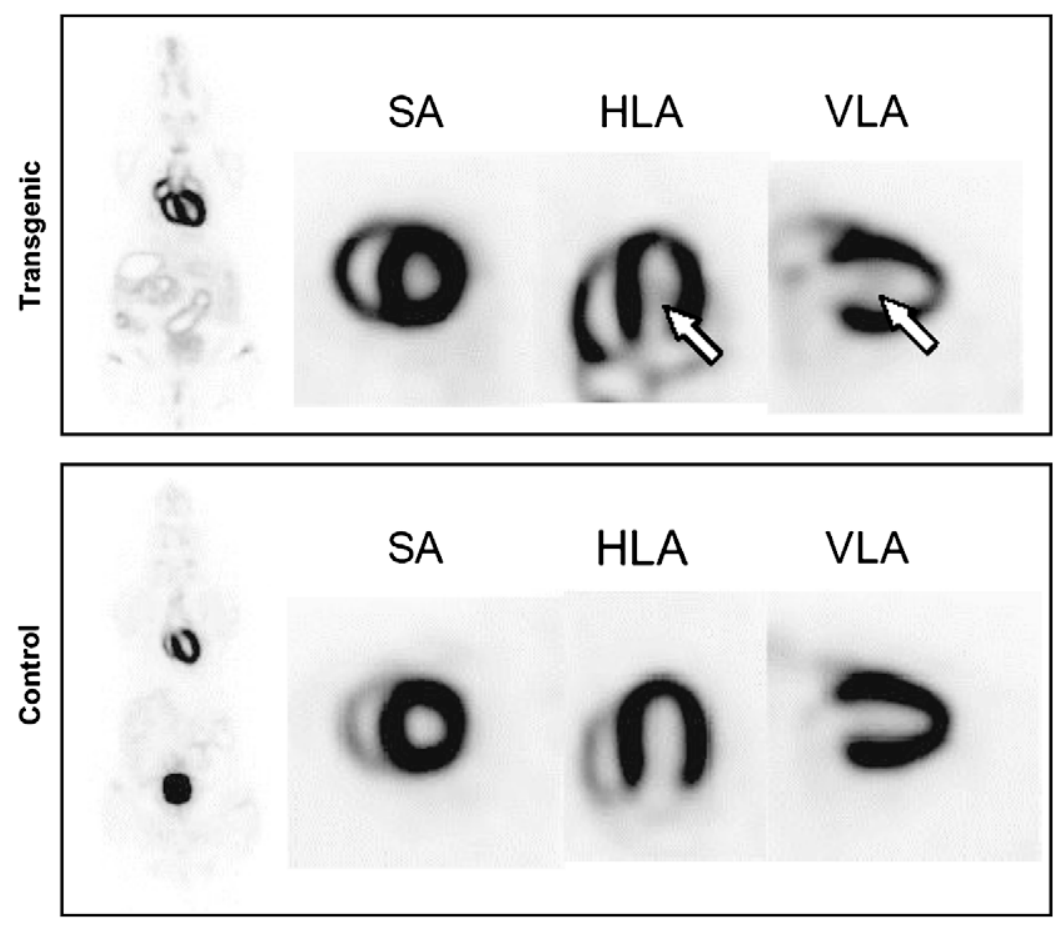

Figure 2. High-resolution positron emission tomographic (PET) scan 1 hour after injection of $10 \mathrm{MBq}$ of 2-[ $\left.{ }^{18} \mathrm{~F}\right]$ fluoro-2-deoxy-D-glucose (FDG) of the transgenic mouse displayed in Figure 1 and an age-matched control animal. Left panel, Whole-body slice through the heart; right panel, short axis (SA), horizontal long axis (HLA), and vertical long axis (VLA) of the heart. Images display enhanced myocardial glucose uptake in the enlarged atria and the right ventricle of the transgenic mouse compared with normal glucose uptake in the control mouse. The left ventricular tumor (arrows) displays a positive FDG-PET signal. However, this signal is relatively low compared with the strong FDG uptake in the myocardium of mice. magnification). This giant spherical tumor occupied about $55 \%$ of the cross-sectional luminal area of the left ventricle. The finding of hemodynamic compromise was further evidenced by means of molecular imaging with high-resolution (FWHM $<1 \mathrm{~mm}$ ) PET scanning with FDG from the same transgenic mouse, featuring an enlargement of both atria and of the right ventricle. In the same mouse the tumor was clearly visible, although the FDG uptake was relatively low compared with the strong signal usually observed in mice (Figure 2). Histology of cardiac tumors showed a considerably enhanced cell density (Figure 3) and enlarged cell nuclei. The average increase in cell density of cardiac tumors
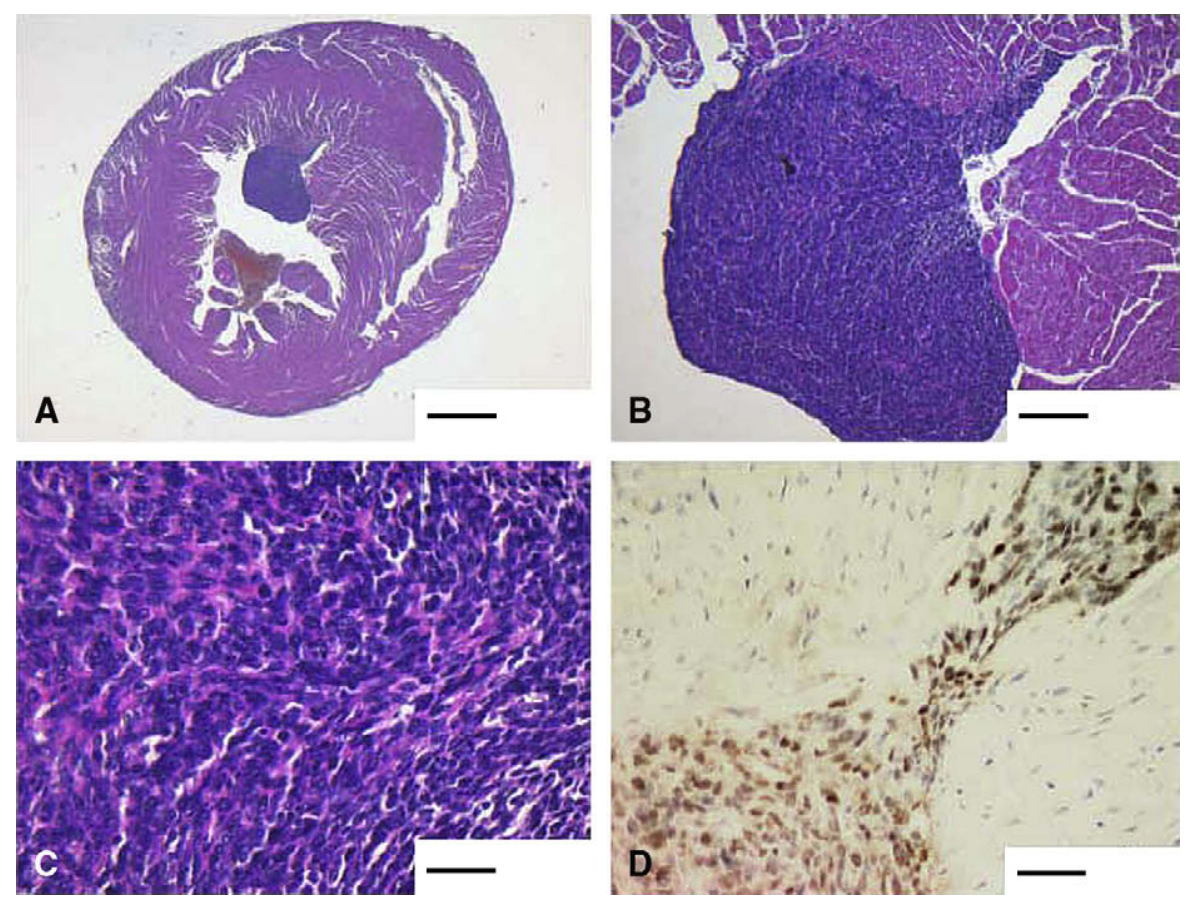

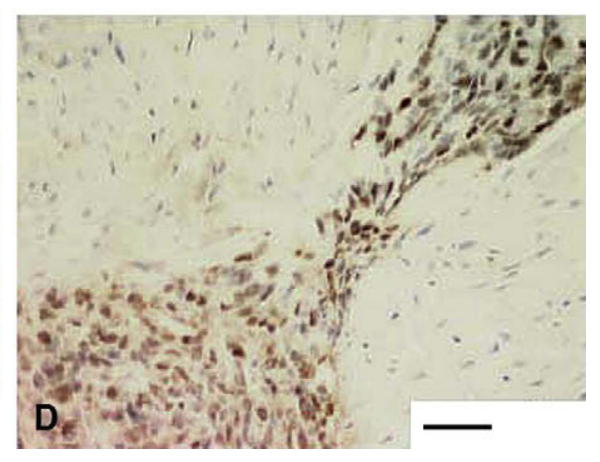

Figure 3. Histologic displays of a left ventricular tumor. The tumor of an approximately 9-week-old transgenic mouse is based at the transition between the wall and the interventricular septum. Panels A through C depict hematoxylin and eosin staining in various magnifications to illustrate the microscopic characteristics of the tumor. Panel D displays immunohistochemical staining for TAg (brown nuclei), which is expressed in the tumor but not in the adjacent regular cardiac muscle (TAg antibody Clone PAb 101; PharMingen, San Diego, Calif; color development was performed with diaminobenzidine and hematoxylin counterstain). Bars: A, $600 \mu \mathrm{m}$; B, $120 \mu \mathrm{m}$; C and D, $30 \mu \mathrm{m}$. 

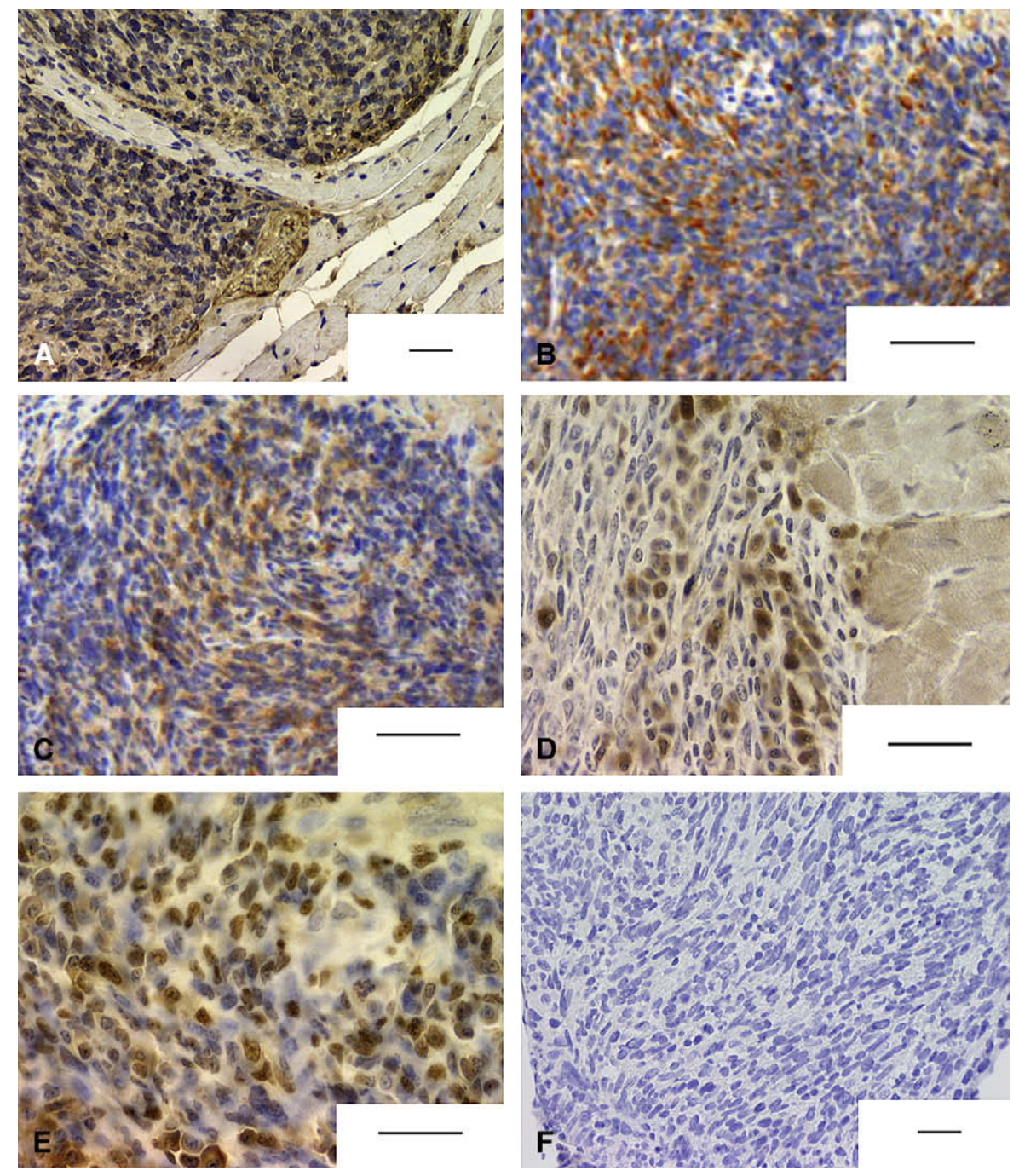

Figure 4. Immunohistochemical staining of a left ventricular tumor of an approximately 9-week old transgenic mouse. Staining was performed as explained in the Methods section. The tumor revealed positive staining for smooth muscle $\alpha$-actin (A), desmin (B), and troponin $C(C)$ and positive staining of single nuclei for Myo D1 (D). In addition, panel E displays immunohistochemical staining for proliferative cell nuclear antigen. Panel $F$ shows a negative control receiving a secondary antibody but no primary antibody. Color development was performed with diaminobenzidine and hematoxylin counterstaining. Bar: $50 \mu \mathrm{m}$. was 3.1-fold compared with the regular heart muscle of control animals ( $\mathrm{n}=8, P<.01)$. Immunohistochemistry revealed the presence of TAg in the cardiac tumors but not in the adjacent regular cardiac muscle, as shown in Figure 3, $D$. Further immunohistochemical analyses of cardiac tumors resulted in positive staining for desmin, smooth muscle $\alpha$ actin, troponin C, and Myo D1 (Figure 4), which met the criteria for rhabdomyosarcomas. The tumors were characterized by a high proliferative activity, as judged by staining for proliferative cell nuclear antigen (Figure 4, E). In addition, we analyzed the DNA content of 5 representative cardiac tumors ( $\mathrm{n}=5$ mice) and found that cardiac tumors showed a mean 3.4-fold increased DNA content compared with the regular cardiac muscle of the same transgenic mice. This increase was significant $(P<.01)$, whereas the DNA content of regular cardiac muscle of transgenic mice was indistinguishable from that of wild-type control animals (data not shown).

\section{Noncardiac Transgene Expression}

In addition to cardiac expression, the transgenic mice (approximately 8-12 weeks of age) also featured transgene expression in smooth muscle tissues, such as arterial vessels, gastrointestinal organs, and genitourinary organs. An overview of smooth muscle expression is shown in Figure 5. In contrast, no transgene expression was found in skeletal muscle. As shown in Figure 5, A, arterial vessels featured patchy transgene expression, resulting in areas of enhanced cell density rather than solid tumor formation, as shown above for cardiac tumors. However, despite localized TAg expression in arterial vessel walls featuring localized enhanced cell density and localized proliferative cell nuclear antigen expression, there was no obstruction or stenosis of the vessels. There was no significant increase in mean aortic wall area, but there was a trend toward an increase in aortic luminal area. The values of the mean cross-sectional wall area of the thoracic aorta were $7.74 \times 10^{4} \pm 1.98 \times 10^{4} \mu \mathrm{m}^{2}$ versus 

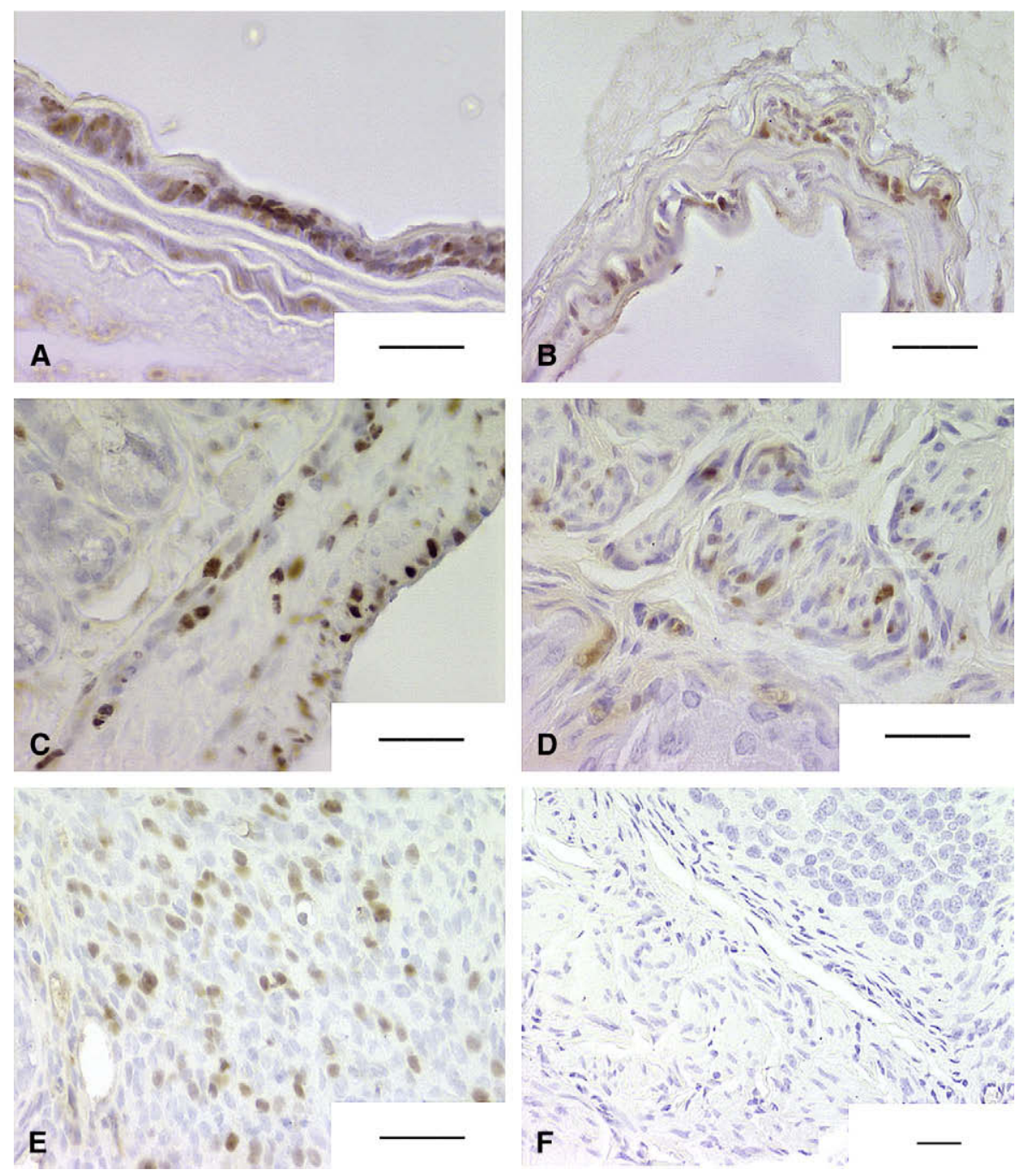

Figure 5. Immunohistochemical staining for $\mathrm{TAg}$ in various smooth musclecontaining tissues of transgenic mice at the age of approximately 9 to 11 weeks. Panel A displays positive TAg staining and increased cellular density, especially in the inner lamellar unit of the thoracic aorta. TAg expression is also shown for the common carotid artery (B). In addition, $\mathrm{TAg}$ expression is also displayed for the smooth muscle of the colon (C), urinary bladder (D), and uterus (E). Panel F shows a negative control (urinary bladder) specimen that received a secondary antibody but no primary antibody. Color development was performed with diaminobenzidine and hematoxylin counterstaining. Bar: $50 \mu \mathrm{m}$.
$6.55 \times 10^{4} \pm 0.89 \times 10^{4} \mu \mathrm{m}^{2}$ for control animals $(\mathrm{n}=8)$. The values for the luminal area were $30.19 \times 10^{4} \pm 12.59$ $\times 10^{4} \mu \mathrm{m}^{2}$ versus $20.88 \times 10^{4} \pm 3.24 \times 10^{4} \mu \mathrm{m}^{2}$, respectively (n $=8, P=.08)$. In one case of an approximately 12-week-old mouse, we found beginning neointima formation in the thoracic aorta (data not shown). Transgene expression was also found in the gastrointestinal tract and the genitourinary tract (urinary bladder and uterus), as shown in Figure 5, $C$ through $E$. It appeared that impairment of bowel function caused by enhanced smooth muscle proliferation was a relevant cause of death in these animals. By evaluating the cell density in areas of transgene expression, we found significant increases in cellular density of TAg-expressing tissue sections compared with levels in wild-type control animals (Figure 6). However, the increases in cell density for the aorta, colon, and bladder were not as pronounced as those found for the cardiac tumors. In conjunction with these findings, the fraction of TAg-expressing cells in vascular, gastrointestinal, and genitourinary tissues was significantly lower than that found for heart tumors, which averaged a fraction of $51.46 \% \pm 11.90 \%(P<.05)$, as shown in Figure 7.

\section{Discussion}

Tumors of the heart are relatively rare. Although first pathoanatomic descriptions date back to Columbus and Zollicofferus in 1559 and 1685 and in vivo diagnosis of primary tumors of the heart was first described in 1934, relatively little is known about the pathogenetic background of this detrimental disease. Most data are based on case reports or small retrospective series. $^{24-29}$ However, reports on the pathogenesis of cardiac rhabdomyosarcoma formation have been rather descriptive, and systematic pathogenetic studies are lacking.

To illuminate the pathophysiology of the most frequent malignant tumors of the heart, the sarcomas, we aimed to establish 


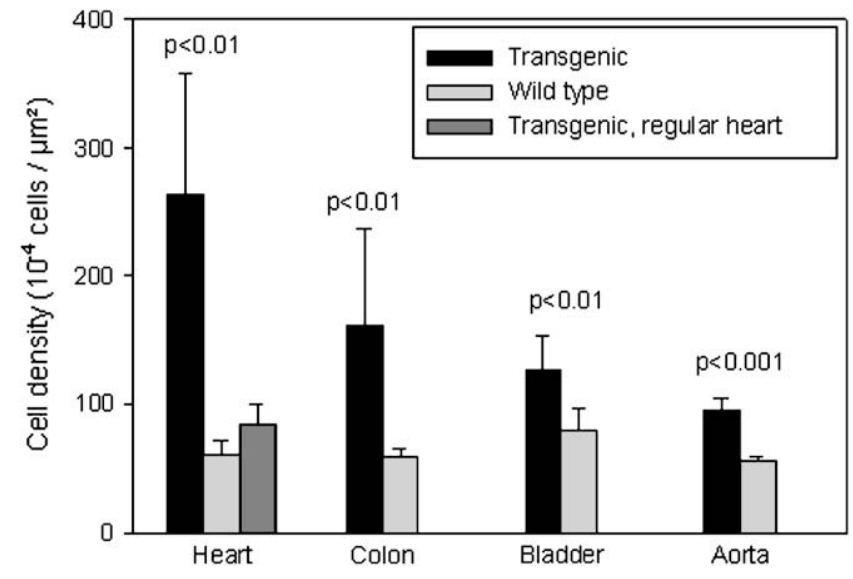

Figure 6. Quantitative analysis of the cellular density of the heart, colon, urinary bladder, and thoracic aorta of transgenic mice and control animals. Cell nuclei of cross-sections were visualized with hematoxylin. Cellular cross-sectional density was determined by counting area-defined representative microscopic fields and relating the cell number to the areas for transgenic animals ( $n$ $=8$; bladder, $n=7$ ) and age-matched control animals $(n=8)$. Cellular density was most pronounced in the cardiac tumors and was significantly higher than in the regular heart tissue of the same transgenic mice (nontumor cardiac tissue) and significantly higher than the cellular density of the hearts of control animals. Data are presented as means \pm standard deviation.

a transgenic mouse model of cardiac rhabdomyosarcoma formation. The availability of such an animal model will be of utmost relevance because it will allow serial testing of pathophysiologic and therapeutic approaches and offers the opportunity to transfer experience from single cases to standardized conditions. This would change the basis of research on cardiac rhabdomyosarcomas from single case reports or small observational series to a systematic approach using an animal model to study, for example, cytogenetics or new therapeutic approaches comprising adjuvant chemotherapy or immunotherapy. To the best of our knowledge, this is the first model of cardiac sarcoma based on genetic modulation. The lack of such a model and the overall rarity of this disease in human subjects make our model a valuable tool for investigations in this field. Other studies have used a toxicologic approach by performing chronic exposure to 1,3-butadiene as a multisite carcinogen to induce cardiac hemangiosarcoma in mice. ${ }^{7}$ Very early studies included a case report of a cardiac rhabdomyosarcoma in a 95-week-old CD1 strain mouse, which is most likely to be interpreted as a combined age and strain effect. $^{30}$ The present model was designed to inactivate tumor suppressors in the heart, such as p53 and proteins of the pRb family, ${ }^{10-13}$ which are targeted through the SM22 $\alpha$ promoter, known to be activated in the embryonic murine heart. ${ }^{18}$ The approach of modulating tumor suppressors, such as p53, is in conjunction with case reports indicating a causative role

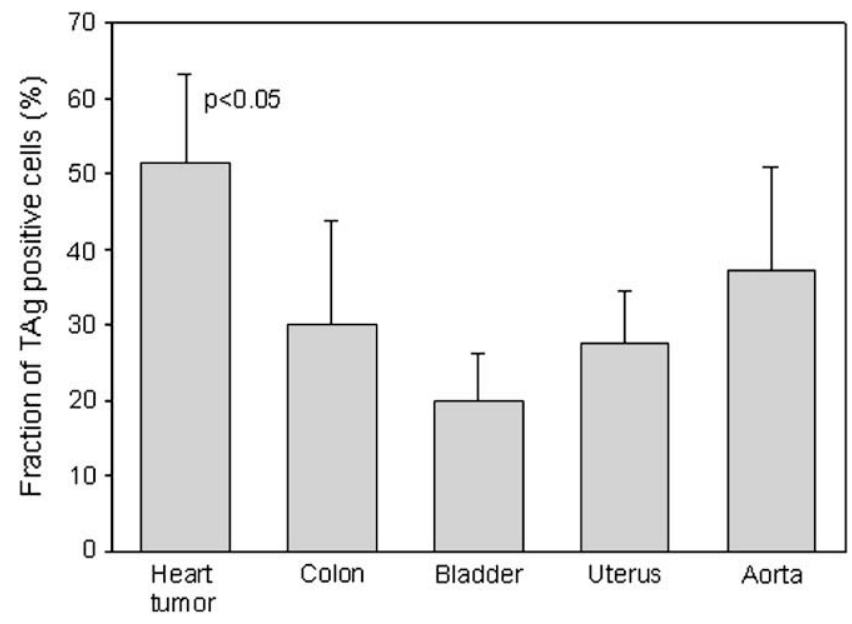

Figure 7. Quantitative analysis of the fraction of TAg-positive cells in the heart tumors $(n=8)$, colon $(n=8)$, urinary bladder $(n=7)$, uterus $(n=7)$, and thoracic aorta $(n=8)$ of transgenic mice. $\mathrm{TAg}$ was detected by means of immunohistochemistry with antibody Clone PAb 101 (PharMingen, San Diego, Calif), as described in the Methods section. Color development was performed with diaminobenzidine. Hematoxylin counterstaining was used for the visualization of all cell nuclei. Fractions of TAg-positive cells were determined by counting area-defined representative microscopic fields. Data are presented as means \pm standard deviation. The fraction of TAg-positive cells in the heart tumors was significantly higher than the fraction of TAg-positive cells in other tissues studied $(P<.05)$.

of this protein in sarcoma formation. ${ }^{6,8,9}$ Targeted expression of TAg in the heart has already been used in earlier studies with other promoters. ${ }^{14-17}$ Transgenic mice expressing atrial natriuretic factor-TAg fusion genes had right atrial tumors composed of differentiated dividing cardiomyocytes. ${ }^{14}$ However, studies using other promoters (atrial natriuretic factor and myosin heavy chain) did not result in the development of cardiac rhabdomyosarcomas (personal communication with Loren $\mathrm{J}$. Field), ${ }^{17}$ indicating that the promoter-specific and time frame-dependent transgene expression might be critical for the development of sarcomas.

The established role of TAg is the inactivation of tumor suppressors, such as $\mathrm{p} 53$ and proteins of the pRb family. ${ }^{10-13}$ This suggests that such a mechanism might play a causative role in the development of cardiac rhabdomyosarcomas in our model. However, the development of solid tumor formation might, at least in part, be dependent on a certain (embryonic) time frame of promoter-targeted inactivation of tumor suppressors, taking into account that studies have shown the earliest expression of SM22 $\alpha$ transcripts in cardiac muscle. ${ }^{18}$ This hypothesis is supported by the finding that TAgtargeted proteins, such as p53 and p107, are both expressed at relatively high levels in embryonic cardiomyocytes. ${ }^{31} \mathrm{It}$ might be discussed for the present model that this setting 
favored the development of a malignant cardiac cell clone the uncontrolled growth of which was perpetuated into adulthood independently of the later promoter function. In contrast, expression of TAg in smooth muscle did not result in obstructing tumor formation at the age studied but rather caused the development of enhanced smooth muscle cell density respecting the anatomic borders, such as arterial lamellar units or the bowel walls. The latter (bowel) finding is essentially comparable with our earlier studies in which TAg was expressed under the control of a smooth muscle myosin heavy chain promoter. ${ }^{32,33}$

The present model of SM22 $\alpha$-targeted TAg expression featured the most intense transgene expression in cardiac tumors, as evidenced by the fraction of TAg-positive cell nuclei. In conjunction, the cardiac tumors presented the highest cell density. Immunohistochemistry revealed the cardiac tumors to stain positive for smooth muscle $\alpha$-actin, troponin C, desmin, and, in a fraction of cells, Myo D1, which met the criteria for cardiac rhabdomyosarcoma. ${ }^{1,24,34,35}$ In the present model the integrity of the expressed transgene was confirmed by means of immunohistochemical staining from an antibody recognizing the $\mathrm{COOH}$-terminal end of $\mathrm{TAg}$. In addition, transgene expression was found to be in line with the promoter function. ${ }^{18}$ These circumstances actually strengthen the conclusion that our findings were attributable to the transgene rather than any secondary factors, such as the disruption of a naturally existing gene or other integration site-specific effects.

Our model will give rise to further studies on the pathogenesis of cardiac rhabdomyosarcoma formation and will pave the way for studying diagnostic and therapeutic options. As an example, recent studies on rhabdomyosarcoma have opened the in vivo use of dasatinib, an inhibitor of src kinase activity, and the blocking of leukemia inhibitory factor. ${ }^{36,37}$ Our model will be an important tool for testing such substances as upcoming therapies for the treatment of cardiac rhabdomyosarcomas. To the best of our knowledge, the present study is the first description of a transgenic mouse model of cardiac rhabdomyosarcoma formation and thus will allow new insights into the pathogenesis and therapeutic targets of this detrimental disease.

We thank Joseph Miano (University of Rochester, Rochester, NY) for providing the SM22 $\alpha$ promoter, and we thank Boris Skryabin (Interdisciplinary Clinical Research Center of the University of Münster, Central project group) for microinjecting purified insert DNA into zygotes. We also thank Keith L. March (Indiana University, Bloomington, Ind) for helpful discussions.

\section{References}

1. McAllister HA Jr, Fenoglio JJ Jr. Tumors of the cardiovascular system. In: Atlas of tumor pathology. Washington, DC: Armed Forces Institute of Pathology; 1978:1-141.

2. Zietz C, Rossle M, Haas C, Sendelhofert A, Hirschmann A, Sturzl M, et al. MDM-2 oncoprotein overexpression, p53 gene mutation, and VEGF up-regulation in angiosarcomas. Am J Pathol. 1998;153:1425-33.
3. Iyengar V, Lineberger AS, Kerman S, Burton NA. Synovial sarcoma of the heart. Correlation with cytogenetic findings. Arch Pathol Lab Med. 1995; 119:1080-2.

4. Hazelbag HM, Szuhai K, Tanke HJ, Rosenberg C, Hogendoorn PC. Primary synovial sarcoma of the heart: a cytogenetic and molecular genetic analysis combining RT-PCR and COBRA-FISH of a case with a complex karyotype. Mod Pathol. 2004;17:1434-9.

5. Palmer JL, Masui S, Pritchard S, Kalousek DK, Sorensen PH. Cytogenetic and molecular genetic analysis of a pediatric pleomorphic sarcoma reveals similarities to adult malignant fibrous histiocytoma. Cancer Genet Cytogenet. 1997;95:141-7.

6. Zu Y, Perle MA, Yan Z, Liu J, Kumar A, Waisman J. Chromosomal abnormalities and p53 gene mutation in a cardiac angiosarcoma. Appl Immunohistochem Mol Morphol. 2001;9:24-8.

7. Hong HH, Devereux TR, Melnick RL, Moomaw CR, Boorman GA, Sills RC. Mutations of ras protooncogenes and p53 tumor suppressor gene in cardiac hemangiosarcomas from $\mathrm{B} 6 \mathrm{C} 3 \mathrm{~F} 1$ mice exposed to 1,3-butadiene for 2 years. Toxicol Pathol. 2000;28:529-34.

8. Naka N, Tomita Y, Nakanishi H, Araki N, Hongyo T, Ochi T, et al. Mutations of p53 tumor-suppressor gene in angiosarcoma. Int J Cancer. 1997;71:952-5.

9. Garcia JM, Gonzalez R, Silva JM, Dominguez G, Vegazo IS, Gamallo C, et al. Mutational status of K-ras and TP53 genes in primary sarcomas of the heart. Br J Cancer. 2000;82:1183-5.

10. Gannon JV, Lane DP. p53 and DNA polymerase alpha compete for binding to SV40 T antigen. Nature. 1987;329:456-8.

11. DeCaprio JA, Ludlow JW, Figge J, Shew JY, Huang CM, Lee WH, et al. SV40 large tumor antigen forms a specific complex with the product of the retinoblastoma susceptibility gene. Cell. 1988;54:275-83.

12. Dyson N, Buchkovich K, Whyte P, Harlow E. The cellular $107 \mathrm{~K}$ protein that binds to adenovirus E1 A also associates with the large T antigens of SV40 and JC virus. Cell. 1989;58:249-55.

13. Wolf DA, Hermeking H, Albert T, Herzinger T, Kind P, Eick D. A complex between E2F and the pRb-related protein p130 is specifically targeted by the simian virus 40 large $\mathrm{T}$ antigen during cell transformation. Oncogene. 1995;10:2067-78.

14. Steinhelper ME, Field LJ. Cardiac tumors and dysrhythmias in transgenic mice. Toxicol Pathol. 1990;18:464-9.

15. Steinhelper ME, Lanson NA Jr, Dresdner KP, Delcarpio JB, Wit AL, Claycomb WC, et al. Proliferation in vivo and in culture of differentiated adult atrial cardiomyocytes from transgenic mice. Am J Physiol Heart Circ Physiol. 1990;259:H1826-34.

16. Katz EB, Steinhelper ME, Delcarpio JB, Daud AI, Claycomb WC, Field LJ. Cardiomyocyte proliferation in mice expressing alpha-cardiac myosin heavy chain-SV40 T-antigen transgenes. Am J Physiol Heart Circ Physiol. 1992;262:H1867-76.

17. De Leon JR, Federoff HJ, Dickson DW, Vikstrom KL, Fishman GI. Cardiac and skeletal myopathy in beta myosin heavy-chain simian virus 40 tsA58 transgenic mice. Proc Natl Acad Sci U S A. 1994;91:519-23.

18. Li L, Miano JM, Cserjesi P, Olson EN. SM22 $\alpha$, a marker of adult smooth muscle, is expressed in multiple myogenic lineages during embryogenesis. Circ Res. 1996;78:188-95.

19. Li L, Miano JM, Mercer B, Olson EN. Expression of the SM22 $\alpha$ promoter in transgenic mice provides evidence for distinct transcriptional regulatory programs in vascular and visceral smooth muscle cells. J Cell Biol. 1996;132:849-59.

20. Fiers W, Contreras R, Haegeman G, Rogiers R, Van de Voorde A, Van Heuverswyn $\mathrm{H}$, et al. Complete nucleotide sequence of SV40 DNA. Nature. 1978;273:113-20.

21. Kim SH, Roth KA, Coopersmith CM, Pipas JM, Gordon JI. Expression of wild-type and mutant simian virus 40 large tumor antigens in villusassociated enterocytes of transgenic mice. Proc Natl Acad Sci U S A. 1994;91:6914-8.

22. Li M, Hu J, Heermeier K, Henninghausen L, Furth PA. Expression of a viral oncoprotein during mammary gland development alters cell fate and function: induction of p53-independent apoptosis is followed by impaired milk protein production in surviving cells. Cell Growth Differ. 1996;7:3-11.

23. Schäfers KP, Reader AJ, Kriens M, Knoess C, Schober O, Schäfers M. Performance evaluation of the 32-module quadHIDAC small-animal PET scanner. J Nucl Med. 2005;46:996-1004. 
24. Vujin B, Benc D, Srdic S, Bikicki M, Vuckovic D, Dodic S. Rhabdomyosarcoma of the heart. Herz. 2006;31:798-800.

25. Hoffmeier A, Etz C, Schmid C, Debus V, Kehl HG, Özgün M, et al. Cardiac transplantation for giant sarcoma of the left ventricle. Circulation. 2005;112:e247-9.

26. Tavil Y, Turkoglu S, Tacoy G, Cemeri M. Huge biatrial cardiac rhabdomyosarcoma resulting in bilateral atrioventricular valve obstruction. Cardiovasc Pathol. 2006;15:354-5.

27. Engelen M, Bruch C, Hoffmeier A, Kersting C, Stypmann J. Primary left atrial angiosarcoma mimicking severe mitral valve stenosis. Heart. 2005;91:e27.

28. Kosuga T, Fukunaga S, Kawara T, Yokose S, Akasu K, Tayama E, et al. Surgery for primary cardiac tumors. Clinical experience and surgical results in 60 patients. J Cardiovasc Surg (Torino). 2002;43:581-7.

29. Thoma-de-Montpreville V, Nottin R, Dulmet E, Serraf A. Heart tumors in children and adults: clinicopathological study of 59 patients from a surgical center. Cardiovasc Pathol. 2007;16:22-8.

30. Gregson RL. A metastasizing cardiac rhabdomyosarcoma in a CD 1 strain mouse. J Comp Pathol. 1984;94:477-80.

31. Kim KK, Soonpaa MH, Daud AI, Koh GY, Kim JS, Field LJ. Tumor suppressor gene expression during normal and pathologic myocardial growth. J Biol Chem. 1994;269:22607-13.
32. Sindermann JR, Babij P, Klink JC, Köbbert C, Plenz G, Ebbing J, et al. Smooth muscle-specific expression of SV40 large TAg induces SMC proliferation causing adaptive arterial remodeling. Am J Physiol Heart Circ Physiol. 2002;283:H2714-24.

33. Sindermann JR, March KL. Balancing luminal size and smooth muscle proliferation - a key control point in atherosclerosis and arteriogenesis. EXS. 2005;94:193-205.

34. Moll R, Holzhausen HJ, Mennel HD, Kuhn C, Baumann R, Taege C, et al. The cardiac isoform of alpha-actin in regenerating and atrophic skeletal muscle, myopathies and rhabdomyomatous tumors: an immunohistochemical study using monoclonal antibodies. Virchows Arch. 2006; 449:175-91.

35. Dias P, Parham DM, Shapiro DN, Tapscott SJ, Houghton PJ. Monoclonal antibodies to the myogenic regulatory protein MyoD1: epitope mapping and diagnostic utility. Cancer Res. 1992;52:6431-9.

36. Wysoczynski M, Miekus K, Jankowski K, Wanzeck J, Bertolone S, Janowska-Wieczorek A, et al. Leukemia inhibitory factor: a newly identified metastatic factor in rhabdomyosarcomas. Cancer Res. 2007;67: 2131-40.

37. Shor AC, Keschman EA, Lee FY, Muro-Cacho C, Letson GD, Trent JC, et al. Dasatinib inhibits migration and invasion in diverse human sarcoma cell lines and induces apoptosis in bone sarcoma cells dependent on SRC kinase for survival. Cancer Res. 2007;67:2800-8. 